\title{
Cardiac Complications in Maroteaux-Lamy Syndrome:
}

\section{Case Report}

Ricardo Siqueira Gonçalves ${ }^{1}$, Claudia Aparecida Marques Landim², Jesuíta Mendes Cornélio ${ }^{3}$ and Joaquim Tomaz da Silva ${ }^{4}$

1. Graduating in Medicine. Universidade do Estado de Mato Grosso-UNEMAT; Liga Acadêmica de Cardiologia e Cirurgia Cardiovascular (LACCIC), Cáceres-MT 78200-000, Brazil

2. Department of Cardiology and Intensive Medicine-Universidade do Estado de Mato Grosso-UNEMAT; Liga Acadêmica de Cardiologia e Cirurgia Cardiovascular (LACCIC), Cáceres-MT 78200-000, Brazil

3. Department of Pediatric Nursing—Hospital Municipal de Unaí-MG (HMU), Unaí-MG 38610-000, Brazil

4. Department of General Surgery—Hospital Municipal de Unaí-MG (HMU), Unaí-MG 38610-000, Brazil

\begin{abstract}
MLS (Maroteaux-Lamy syndrome) or MPS VI (mucopolysaccharidosis VI) is an autosomal recessive pathology in which there is absence or low activity of the enzyme N-Acetylgalactosamine-4-Sulfatase, which hydrolyzes GAGs (glycosaminoglycans) in the body (mainly dermatan sulfate). Consequently, there occurs lysosomal deposition of GAGs in connective tissue multisystemic. Myocardium and heart valves are frequently affected structures, presenting a direct correlation with the reports of complications and deaths. Case report: RGS, male, 3 years and 2 months, diagnosed with MPS VI from the first month of life, in weekly ERT (enzyme replacement therapy) since 4 months of age (inconstant). At physical examination: normotensive, with holosystolic heart murmur 3+/6+ in mitral focus. Complementary tests: normal electrocardiogram, echocardiogram with pronounced mitral regurgitation, concentric left ventricular hypertrophy of moderate degree and mild aortic insufficiency. Discussion: Mitral valve disease is common in patients with MLS. Conditions such as cardiomyopathy, fibroelastosis, aneurysm and pulmonary hypertension may occur in these patients, indicative of morbidity and mortality. Early and constant ERT may be useful in slowing a progression of heart disease. Conclusions: follow-up with a cardiologist is important to evaluate the progression of cardiac complications in MPS VI. Constant and early ERT provides better prognosis for these patients.
\end{abstract}

Key words: Mucopolysaccharidosis VI, N-acetylgalactosamine-4-sulfatase, mitral valve insufficiency, enzyme replacement therapy.

\section{Introduction}

Described in 1963 by Pierre Maroteaux and Maurice Lamy [1], MLS (Maroteaux-Lamy syndrome) or MPS VI (mucopolysaccharidosis VI) is a rare pathology of autosomal recessive origin. It is a disease originating from innate errors of metabolism, in which there is a reduction or absence of activity of the lysosomal enzyme N-acetyl-galactosamine-4-sulfatase or ARSB (arisulfatase B), resulting from mutations with in gene encoding it, located on the chromosome 5 (5q13-5q14). The ARSB is responsible for hydrolysis of the GAGs

Corresponding author: Ricardo Siqueira Gonçalves, medical student, research fields: cardiology and cardiovascular surgery. (glycosaminoglycans): DS (dermatan sulfate) and chondroitin 4-sulfate. As a result of this abnormality, there is lysosomal deposition of GAGs (predominantly DS) in the connective tissue of the whole organism [1, 2].

In Brazil, the prevalence of MPS VI was estimated at $0.083 / 100,000$ inhabitants, with a higher prevalence in the northeast region $(0.102 / 100.000)$ [3, 4]. The diagnosis of MLS is based on the clinical picture, urinary increase in the excretion of GAGs and a finding of the decrease or absence of the ARSB enzymatic activity. Besides that, the genetic mutation associated with the pathology also can be identified [4]. The main treatment is through ERT (enzyme replacement 
therapy) with galsulfase (recombinant form of the ARSB enzyme), approved in the USA by FDA (Food and Drugs Administration) in 2005 and in Brazil by the ANVISA (National Agency of Sanitary Surveillance) since 2009 [4, 5].

MPS VI is a broad-spectrum clinical disease, with multisystem manifestations. The myocardium and cardiac valves are structures that are frequently affected, being of great importance due to direct correlation with increased morbidity and mortality in these patients [1-9].

Below was reported a case of cardiac complications in a patient with MPS VI.

\section{Case Report}

RGS, male, 3 years and 2 months, with confirmed diagnosis of MPS VI since the first month of life (older sibling with the same pathology), in weekly ERT with galsulfase since 4 months (inconstant, due to the socioeconomic difficulty of the family in moving to the city where the preschooler does the treatment). Mother says that child shows tiredness to efforts. Syndromic patient, in good general condition, normotensive, presenting to the cardiopulmonary physical examination: respiratory auscultation with vesicular murmurs present in both hemithorax, with the presence snoring of moderate-intensity; cardiac auscultation with regular rhythm, in two times, normal sounds with presence of holosystolic heart murmur $3+/ 6+$, better audible in mitral focus; ictus cordis not palpable due to anatomical alteration of the rib cage; well perfused limbs, symmetrical peripheral pulses and large. Complementary examinations: ECG (electrocardiogram) (Fig. 1): sinus rhythm, without abnormalities (analysis done according to table by Davignon et al. by age group) [10]. Echocardiogram (Fig. 2): Severe mitral regurgitation (thickened mitral valve, shortened anterior leaflet and pronounced regurgitation); Moderate ventricular concentric hypertrophy of the left ventricle; Discrete aortic insufficiency; Ejection fraction: 73.7\%. Until the moment, the patient has been undergoing treatment with weekly ERT (inconstant) and being monitored annually by the cardiologist, where the possibility of future mitral valve replacement surgery was discussed.

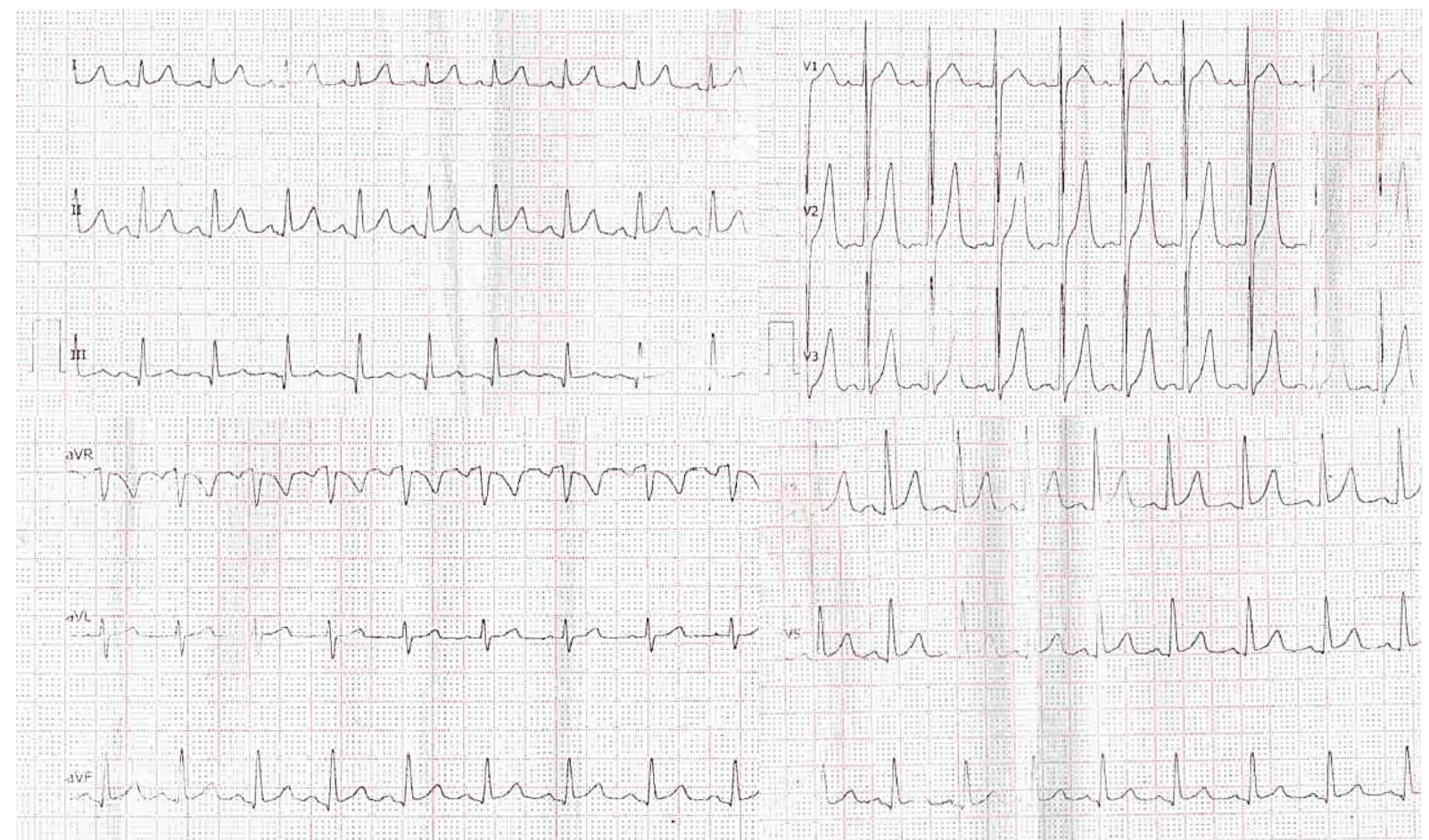

Fig. 1 Electrocardiogram with parameters within normality for age group according to Davignon et al. 


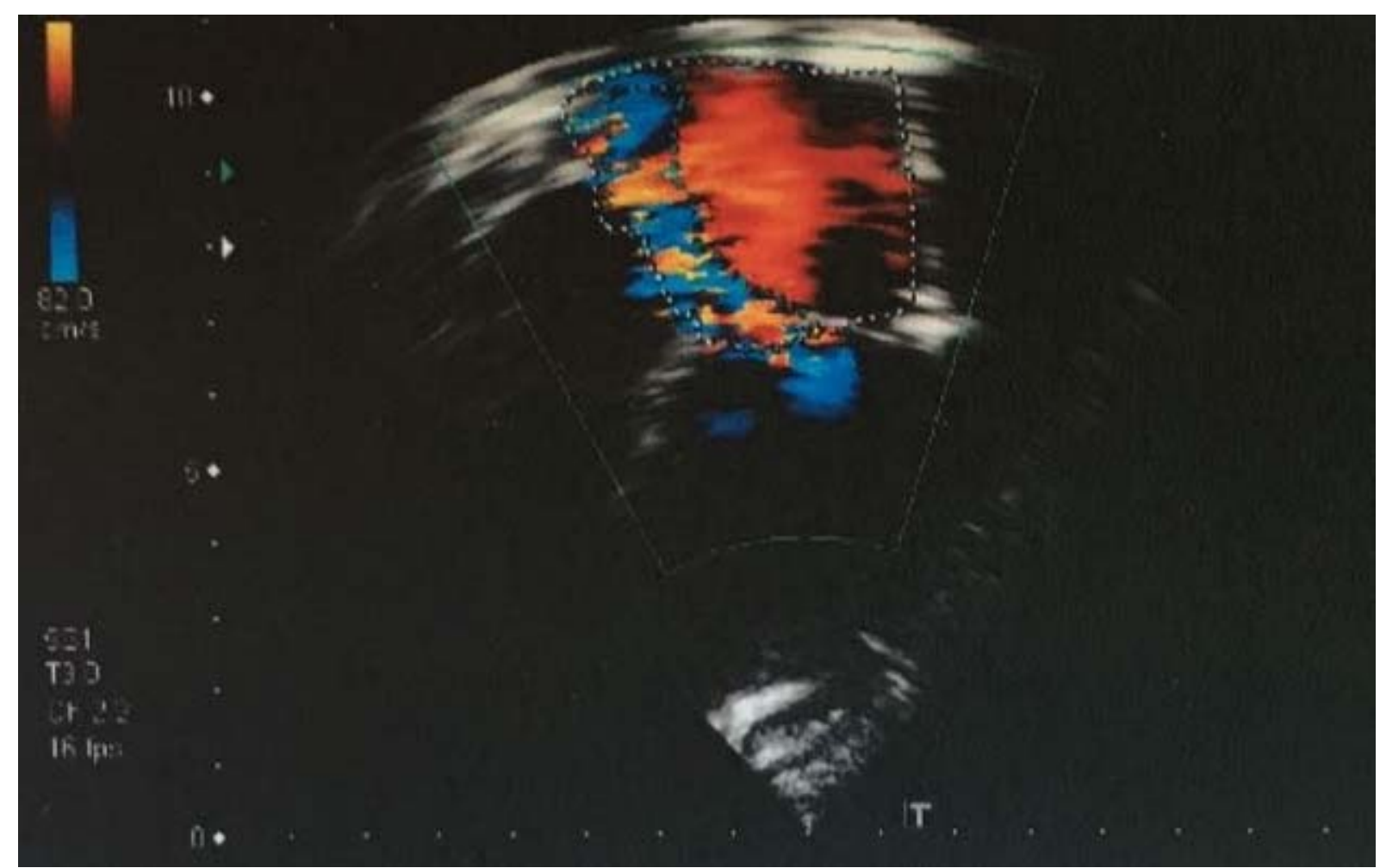

Fig. 2 Severe mitral regurgitation, due to thickening of the mitral valve, with shortening of the anterior leaflet and consequent regurgitation.

\section{Discussion}

The manifestations of heart disease in patients with MPS VI are of great relevance due to the increased morbidity and mortality, associated with poorer quality and lower life expectancy [1-9]. The heart valves are the structures most affected by the disease. Progressive degeneration occurs leading to the valvular insufficiency and / or stenosis, constituting the primary cardiac manifestations in MLS [2]. In addition, the left (mitral and aortic) valves are more affected than the rights (tricuspid and pulmonary), being more common the insufficiency than the stenosis [6]. Mitral regurgitation is the most common valve manifestation in patients with MPS VI, occurring in more than 95\% of the cases [3], being also the main manifestation occurred in the patient reported here.

Valve involvement in MLS involves the excessive accumulation of DS (which is normally already part of the physiological composition of the valves), leading to inhibition of the formation of elastic fibers and stimulation of inflammatory process with consequent fibrosis and valve calcification. The valve insufficiency and/or stenosis caused by these histological alterations can lead to the formation of heart murmurs. However, during the cardiovascular examination of a patient with MPS VI, the absence of heart murmurs does not exclude the presence of significant heart disease. This is because auscultation frequently can be hampered by the intensity of airborne noises and deformity of the thoracic cavity (due to the systemic manifestation of the pathology), making it difficult to perceive the murmurs [6]. Although with an important thoracic deformity and presence of important air noises, the heart murmur was heard in the patient reported here, alerting to the possible severity of its valve complication.

The entire cardiovascular system of patients may be compromised in MLS, although cardiac valves are commonly and initially the most affected. The structure and function of the endocardium, myocardium, coronary arteries, conduction systems, large vessels and systemic vascularization may be altered as a result 
of accumulations of DS in cytoplasmic vacuoles of endothelial cells, myocytes and fibroblasts of cardiovascular tissue [7]. Complications such as cardiomyopathy, occlusion of coronary arterioles (due to thickening of the intima layer), left ventricular aneurysm [6, 11] and fibroelastosis [12] have been described in the literature. The presence of pulmonary hypertension is an important component of poor prognosis in these patients [2].

Medical follow-up of these patients with a cardiologist should be periodic, every one to two years. Physical examination, blood pressure measurement, ECG and transthoracic echocardiography (ECOT) are essential assessments [2, 6]. As a limitation, we have the fact that the ECG may not visualize some cardiac changes, such as the presence of ventricular overloads, for example. This is due to increased electrical resistance by tissues rich in GAGs, which reduce the amplitude of the electrocardiographic tracing in the precordial leads. This situation was present in the case reported here, in which, although the patient had a ventricular overload evidenced by ECOT, no change to the ECG compatible with the overload was observed.

The electrocardiographic limitation described above reinforces the importance of ECOT in the patient with MPS VI. It is a very cost-effective and non-invasive exam. Through it one can evaluate the patient's cardiac function and its degrees of impairment, mainly valvular, which is the most frequently affected structure [2, 6].

MLS is a disease that has no cure. Its treatment options include hematopoietic cell transplantation and ERT, which is the most commonly used. The benefit of ERT in cardiovascular complications is in delaying the natural progression of valvular disease, especially if started early (before 5 years of age) and in the absence of pre-established cardiac complications [7-9]. However, in order to achieve this benefit, it is of the utmost importance that the treatment be done continuously, without interruption [7].

In the study by Leal et al., discontinuation of medications was associated with loss of improvements achieved with enzyme replacement and increased excretion of urinary GAGs, showing greater activity of the disease. This can be compared to the case reported here, in which the RGS patient, even having started ERT early, has an important degree of cardiac complication. This is due not only to the rapidly progressive nature of their pathology, but also to the fact that their ERT is inconstant (due to socioeconomic problems) and does not generate the expected effect of delaying the natural progression of the pathology.

\section{Conclusions}

MLS is a very rare condition, with frequent heart involvement and important consequences. Patients with MPS VI who present with cardiac complications need special attention due to the potential that such changes may cause worsening of the general clinical picture and decrease in life expectancy. They should be monitored periodically by a cardiologist (every one or two years), with physical examination (including blood pressure measurement), electrocardiogram and echocardiogram.

In addition to the institution of early ERT, it is important that it be done in a constant way, to guarantee the desired and beneficial effect of the medication, mainly in the delay of the rate of natural progression of valve disease. This concept represents an important socioeconomic challenge in the treatment of the patient with MPS VI mentioned here, directly reflecting in their prognosis.

\section{Declaration of Interest}

I declare there is no conflict of interest.

\section{References}

[1] Politei, J., Schenone, A., Blanco, M., and Szlago, M. 2014. "Mucopolisacaridosis VI: aspectos clínicos, diagnósticos y del tratamiento con terapia de reemplazo enzimático.” Arch Argent Pediatr 112 (3): 258-62.

[2] Golda, A., Jurecka, A., Opoka-Winiarka, V., and Tylki-Szymánska, A. 2013. "Mucopolysaccharidosis Type VI: A Cardiologist's Guide to Diagnosis and Treatment.” International Journal of Cardiology 167: 
1-10.

[3] Martins, A. M., et al. 2009. "Prevalence of MPS VI Patients in Brazil [abstract].” Molecular Genetics and Metabolism 98 (1-2): 86.

[4] Gomes, B. S. D., Nóbrega, C. E. B., Medeiros, P. F. V., Medeiros, I. A. M. C., and Pordeus, A. C. B. 2011. "Manifestações Cardíacas em Pacientes com Mucopolissacaridose VI: relato de caso.” Rev Bras Ecocardiogr Imagem Cardiovasc 24 (1): 88-92.

[5] Giugliani, R., et al. 2010. "Mucopolysaccharidosis I, II, and VI: Brief Review and Guidelines for Treatment." Genetics and Molecular Biology 33 (4): 589-604.

[6] Braulin, E. A. et al. 2011. "Cardiac Disease in Patients with Mucopolysaccharidosis: Presentation, Diagnosis and Management.” J Inherit Metab Dis 34: 1183-97.

[7] Leal, G. N., Paula, A. C., Morhy, S. S., Andrade, J. L., and Kim, C. A. 2014. "Advantages of Early Replacement Therapy for Mucopolysaccharidosis Type VI: Echocardiographic Follow-up of Siblings.” Cardiology in the Young 24: 229-35.

[8] Muenzer, J. 2014. "Early Initiation of Enzyme
Replacement Therapy for the Mucopolysaccharidosis.” Molecular Genetics and Metabolism (111): 63-72.

[9] Horovitz, D. D. G., et al. 2013. "Enzyme Replacement Therapy with Galsulfase in 34 Children Younger Than Five Years of Age with MPS VI.” Molecular Genetics and Metabolism (109): 62-9.

[10] Pastore, C. A., Pinho, J. A., Pinho, C., Samesima, N., Pereira-Filho, H. G., Kruse, J. C. L., et al. 2016. “III Diretrizes da Sociedade Brasileira de Cardiologia sobre análise e emissão de laudos eletrocardiográficos.” Arq Bras Cardiol 106 (4Supl.1): 1-23.

[11] Oudit, G. Y., Butany, J., Williams, W. G., Siu, S. C., Clarke, J. T. R., and Iwanochko, R. M. 2007. "Left Ventricular Aneurysm in a Patient with Mucopolysaccharidosis Type VI (Maroteaux-Lamy Syndrome): Clinical and Pathological Correlation.” Cardiovasc Pathol 16: 237-40.

[12] Fong, L. V., Menahem, S., Wraith, J. E., and Chow, C. H. 1987. "Endocardial Fibroelastosis in Mucopoly Saccharidosis Type VI: Case Reports.” Clin. Cardiol 10: 362-4. 